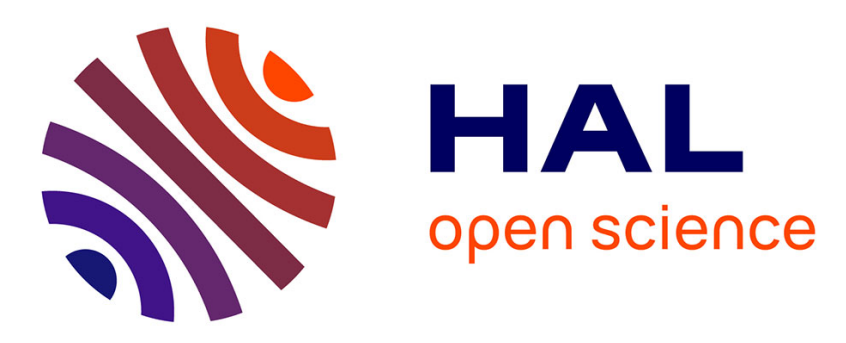

\title{
Role of Nucleic Acid Binding in Sir3p-Dependent Interactions with Chromatin Fibers
}

Nicholas L Adkins, Steve J Mcbryant, Cotteka N Johnson, Jennifer M Leidy, Christopher L Woodcock, Charles Robert, Jeffrey C Hansen, Philippe T

Georgel

\section{To cite this version:}

Nicholas L Adkins, Steve J Mcbryant, Cotteka N Johnson, Jennifer M Leidy, Christopher L Woodcock, et al.. Role of Nucleic Acid Binding in Sir3p-Dependent Interactions with Chromatin Fibers. Biochemistry, 2009, 48 (2), pp.276-288. 10.1021/bi801705g · hal-02988876

\section{HAL Id: hal-02988876 https://hal.science/hal-02988876}

Submitted on 4 Nov 2020

HAL is a multi-disciplinary open access archive for the deposit and dissemination of scientific research documents, whether they are published or not. The documents may come from teaching and research institutions in France or abroad, or from public or private research centers.
L'archive ouverte pluridisciplinaire HAL, est destinée au dépôt et à la diffusion de documents scientifiques de niveau recherche, publiés ou non, émanant des établissements d'enseignement et de recherche français ou étrangers, des laboratoires publics ou privés. 


\section{Article}

\section{Role of Nucleic Acid Binding in Sir3p-Dependent Interactions with Chromatin Fibers}

Nicholas L. Adkins, Steve J. McBryant, Cotteka N. Johnson, Jennifer M. Leidy, Christopher L. Woodcock, Charles H. Robert, Jeffrey C. Hansen, and Philippe T. Georgel Biochemistry, Article ASAP • DOI: 10.1021/bi801705g

Downloaded from http://pubs.acs.org on January 5, 2009

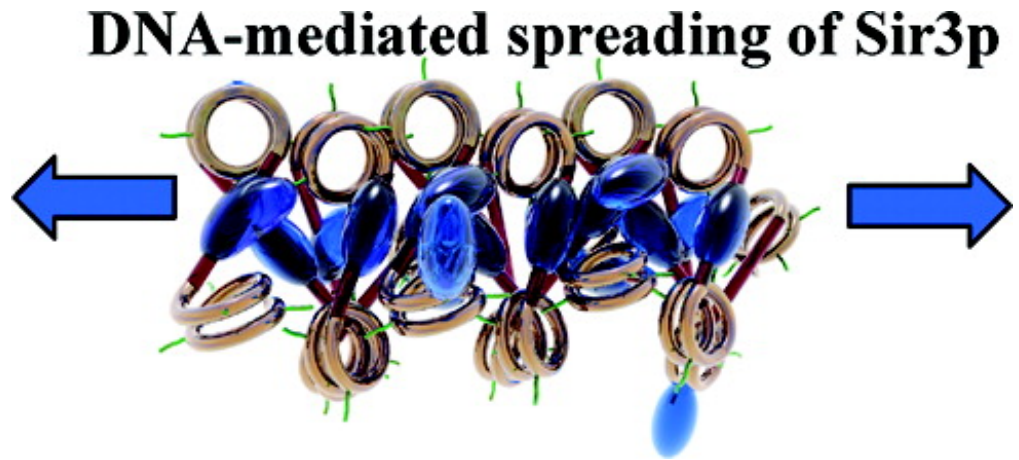

\section{More About This Article}

Additional resources and features associated with this article are available within the HTML version:

- $\quad$ Supporting Information

- Access to high resolution figures

- $\quad$ Links to articles and content related to this article

- Copyright permission to reproduce figures and/or text from this article

\section{View the Full Text HTML}




\title{
Role of Nucleic Acid Binding in Sir3p-Dependent Interactions with Chromatin Fibers $^{\dagger}$
}

\author{
Nicholas L. Adkins, ${ }^{\ddagger}$ Steve J. McBryant,${ }^{\S}$ Cotteka N. Johnson, ${ }^{\ddagger}$ Jennifer M. Leidy, ${ }^{\ddagger, l l}$ Christopher L. Woodcock, ${ }^{\perp}$ \\ Charles H. Robert, ${ }^{\#}$ Jeffrey C. Hansen, ${ }^{\S}$ and Philippe T. Georgel ${ }^{*, *}$ \\ Department of Biological Sciences and Cell Differentiation and Development Center, Marshall University, \\ Huntington, West Virginia 25755, Department of Biochemistry and Molecular Biology, Colorado State University, Fort Collins, \\ Colorado 80523-1870, School of Medicine, West Virginia University, Morgantown, West Virginia 26506-9100, Department of \\ Biology, University of Massachusetts, Amherst, Amherst, Massachusetts 01003, and CNRS, Institut de Biochimie et Biophysique \\ Moléculaire et Cellulaire, Université Paris Sud, Orsay 91405, France
}

Received September 8, 2008; Revised Manuscript Received November 10, 2008

\begin{abstract}
Recent studies of the mechanisms involved in the regulation of gene expression in eukaryotic organisms depict a highly complex process requiring a coordinated rearrangement of numerous molecules to mediate DNA accessibility. Silencing in Saccharomyces cerevisiae involves the Sir family of proteins. Sir3p, originally described as repressing key areas of the yeast genome through interactions with the tails of histones $\mathrm{H} 3$ and $\mathrm{H} 4$, appears to have additional roles in that process, including involvement with a DNA binding component. Our in vitro studies focused on the characterization of Sir3p-nucleic acid interactions and their biological functions in Sir3p-mediated silencing using binding assays, EM imaging, and theoretical modeling. Our results suggest that the initial Sir3p recruitment is partially DNA-driven, highly cooperative, and dependent on nucleosomal features other than histone tails. The initial step appears to be rapidly followed by the spreading of silencing using linker DNA as a track.
\end{abstract}

The regulation of gene expression in eukaryotes is dependent on several sets of proteins that regulate DNA accessibility. In this context, the level of chromatin compaction plays a central role in the transition from a transcriptionally active to a repressed state. In yeast, gene silencing requires the establishment of a specific chromatin configuration that displays a high level of similarity to the heterochromatin conformation observed in higher eukaryotes. Saccharomyces cerevisae possesses a set of specialized proteins called silent information repressors $\left(\mathrm{Sir}^{1} 1-4(1)\right)$ that, in combination with ORC1 and RAP1, promote nucleation and spreading of silencing at specific loci (2). Sir2 is a NAD-dependent histone deacetylase (1), and Sir3p and Sir4p are structural chromatin-associated proteins initially described as N-terminus binding partners for histones $\mathrm{H} 3$ and H4 (2-6). The mechanism of Sir-mediated silencing is intimately linked with structural modifications of chromatin $(3,4,7)$. The recruitment of Sir3 and Sir4 has initially been

\footnotetext{
${ }^{\dagger}$ This work was supported by National Science Foundation EPSCoR Grant EPS-0554328 (P.T.G.) and NIH Grant GM66834 (J.C.H.). The use of the Genomic Core Facility at Marshall University was supported by NIH Grant 5P20RR-020180.

* Corresponding author. Phone: 304-696-3965. Fax: 304-696-7136. E-mail: georgel@marshall.edu.

* Marshall University.

$\S$ Colorado State University.

"West Virginia University.

${ }^{\perp}$ University of Massachusetts, Amherst.

\# Institut de Biochimie et Biophysique Moléculaire et Cellulaire.

${ }^{1}$ Abbreviations: Sir, silent information regulator; EM, electron microscopy; FWJ, four-way junction; EMSA, electrophoretic mobility shift assay; NA, nucleosomal arrays; QAGE, quantitative agarose gel electrophoresis; $R_{\mathrm{e}}$, effective radius; $P_{\mathrm{e}}$, pore size; TPE, telomere position effect.
}

described as a process mediated by their binding to the histone tails of $\mathrm{H} 3$ and $\mathrm{H} 4(3,4)$, although biochemical data indicate that the tails are not needed for binding to chromatin in vitro $(8,9)$. Recent publications have also indicated a potential role for double-stranded DNA (dsDNA) in the establishment of silencing theorizing that the DNA itself may provide a means for establishment and/or spreading of silencing $(7,10)$. Our initial experiments suggested that Sir3p would bind more readily to the linker DNA in chromatin than to DNA wrapped around a histone octamer, but in a different manner than that of linker histone (7). In addition, the Sir3p concentration was shown to affect chromatin fiber-fiber interactions, resulting in potential large-scale chromatin reorganization (7).

The goal of this study is to provide a better delineation of the role of nucleic acids in the Sir3p-mediated recruitment and formation of supramolecular structures in vitro. To this end, we have carried out experiments using normal and tailless nucleosome arrays as controls, as well as nucleic acid fragments of various compositions, lengths, and conformations. The study also includes analysis of Sir3p binding as a function of Sir3p and DNA concentrations to mimic possible changes in local concentrations within the nucleus.

To determine the effect of DNA conformation on Sir3p recruitment, we used several short linear DNA fragments with various intrinsic bendabilities. Our results indicate that Sir3p does not significantly differentiate between linear, curved, or bent DNA. However, a synthetic four-way junction (FWJ) designed to mimic the nucleosomal entry-exit DNA region (11) is a poorer substrate for DNA binding. Using a binding assay employing DNA fragments of 
decreasing sizes, we determined that Sir3p binding occurs over templates as small as $12 \mathrm{bp}$. Finally, we investigate the influence of Sir3p molarity on intermolecular DNA bridging using either DNA, nucleosomal arrays (NA), or trypsinized or tailless NAs as binding templates and find that an increased local concentration promotes DNA bundling. Electron microscopy images are consistent with our electrophoretic mobility shift assay (EMSA) results and demonstrate the presence of Sir3p-induced layered DNA fragments. In combination with our observations that Sir3p can efficiently form complexes with tailless NA $(7,9)$, we conclude that the mechanism by which Sir3p induces gene silencing not only is associated with histone tails but is in part DNA-driven.

\section{EXPERIMENTAL PROCEDURES}

Sir3p Purification. The protein was purified from SF9 cells infected with a recombinant bacculovirus containing a recombinant Sir3p sequence fused to six C-terminal histidines $(7,13)$. After $40 \mathrm{~h}$, nuclear extracts prepared from infected cells were purified through a Ni affinity chromatography column followed by Q-Sepharose (13). After purification, Sir3p was dialyzed against H5EGN (5 mM HEPES, $0.1 \mathrm{mM}$ EDTA, $5 \%$ glycerol, $10 \mathrm{mM} \mathrm{KCl}, 0.1 \%$ NP-40). The concentration was determined by spectroscopy based on the extinction coefficient and confirmed by comparison to BSA standards after SDS-PAGE as described in Georgel et al. (14). Alternatively, Sir3p was overexpressed and purified from a bacterial system as follows. Sir3p was expressed from pJC52 (7) in BL21 cells (Stratagene). Expression was induced by addition of IPTG to a final concentration of $1 \mathrm{mM}$ for $5 \mathrm{~h}$ in the presence of $3 \%$ ethanol. Sir3p was purified using a TALON metal affinity resin (Clontech) according to the manufacturer's specifications. The protein was subsequently dialyzed against H5EGN, and the concentration was calculated by comparing Coomassie blue staining against that of purified BSA and confirmed by spectroscopy based on the extinction coefficient. Note that both forms of Sir3p displayed indistinguishable nucleic acid and chromatin binding properties when used for titration experiments.

DNA and Nucleosomal Arrays. The 208-7 and 208-12 DNA templates containing repeats of the 5S rDNA from Lytechinus variegatus were purified from plasmids pPol I 208-7 and pPol I 208-12 (15), after digestion with HhaI, followed by gel-filtration purification, as described in Hansen et al. (16). Histone octamers were purified from chicken erythrocytes (15), and tailless histones were prepared by limited trypsin digestion as described by Fletcher and Hansen (17). Nucleosome arrays (normal or tailless) were reconstituted by salt dialysis at a ratio of $1.1 \mathrm{~mol}$ of octamer to 1 mol of 208 bp DNA (18). The efficiency of reconstitution was analyzed by ultracentrifugation and quantitative agarose gel electrophoresis (QAGE), as described by Fletcher et al. (19).

PCR Fragments and Oligomers Used for Gel Electrophoresis Analysis. The linear DNA fragment referred to as "straight" was prepared by PCR amplification using the plasmid pdHSP XA 0.5 (20) as the template and primers p1 and $\mathrm{p} 2$ encompassing positions -185 to -165 (p1: 5'TCG AGA AAT TTC TCT GGC CG3') and +18 to +36 (p2:
5'TTC GCG ATG TGT TCA CCT3') from the Drosophila hsp70 gene. The $199 \mathrm{bp}$ "bent" fragment encompassing the Acanthamoeba histolitica RNA polymerase 1 binding site was generated from the plasmid pPol I 208-12 (15) using primers p3 (5'CGC TCG TTT TAC AAC GTC3') and p4 (5'CCG CAC AGA TGC GTA AGG3').

The 208-1 5S rDNA was used as a source of material for the "curved" fragment. It was prepared by AvaI digestion of the 208-12 DNA fragment (10 units/ $\mu \mathrm{g}$ of DNA for 60 min at $37^{\circ} \mathrm{C}$ ) and gel-purified after electrophoresis in a $1 \%$ agarose gel. The $100 \mathrm{bp}$ fragment was prepared by PCR amplification (primers). The $50 \mathrm{bp}$ fragment was also PCRamplified using primers p5 (5'TCG ACG AAG CGC CTC T3') and p6 (5'AGG CGC GCT CTC TCT C3') and the plasmid pdHSPXA 0.5 as template (20).

The $32 \mathrm{bp}$ fragment was generated by annealing primers p7 (5'TTC AGG CGC GCG CTA GCG AAG CAA CAG AG3') and p8 (5'CTC TGT TGC TTC GCT AGC GCC CGC CTG AA3'). The $12 \mathrm{bp}$ fragment was generated similarly by annealing primers $\mathrm{p} 9$ (5'TCA CTT ATT TGT3') and p10 (5'ACA AAT AAG TGA3').

Evaluation of DNA Curvature. The "straight", "bent", and "curved" DNA conformations were assessed by QAGE, and the DNA fragments were electrophoresed in multigel as described in Fletcher et al. (18). The effective radii $\left(R_{\mathrm{e}}\right)$ were determined using the equation:

$$
\mu / \mu_{\mathrm{o}}^{\prime}=\left(1-R_{\mathrm{e}} / P_{\mathrm{e}}\right)^{2}
$$

where $\mu$ represents the mobility of the fragments, $\mu_{\mathrm{o}}^{\prime}$ is the surface-charge density, $R_{\mathrm{e}}$ is the effective radius, and $P_{\mathrm{e}}$ is the pore size of the agarose gels [500 ng of DNA plus 500 ng of T3 phage (used as an internal marker)]. After $4 \mathrm{~h}$ of electrophoresis at $1.33 \mathrm{~V} / \mathrm{cm}$ in TAE buffer, the multigels were stained with SYBR green for $30 \mathrm{~min}$. The distances of migration of all samples were measured, and $P_{\mathrm{e}}$ was calculated from the information obtained from the concomitant electrophoresis of the T3 phage internal marker, whose known size allows calibration (19). The DNA conformations and overall curvatures were then estimated based on their respective sizes and $R_{\mathrm{e}}$ values. The theoretical calculations to determine the conformation of the DNA fragments were performed using the Trifonov algorithm, as described in Georgel and Robert (22).

Reconstitution of a Four-Way Junction. The four-way junction template was assembled from four separate oligonucleotides (FWJ1, GATCCTAGGCCTCACGTATTATATCGATGCATGCG; FWJ2, AATTCGACGATCGAAGCTGAATACGTGAGGCCTAGG; FWJ3, ACCATGCTCGAGATTACGAGCAGCTTCGATCGTCG; FWJ4, TTCGC A T G C A T GCA T C G A T A T C T C G T A A T C T C GAGCATGG) and by sequentially annealing equimolar amounts of two subsets of single-stranded oligos at $65^{\circ} \mathrm{C}$. First, oligonucleotides FWJ2 and FWJ3 were incubated in standard TE buffer (10 $\mathrm{mM}$ Tris $\mathrm{HCl}$ and $1 \mathrm{mM}$ EDTA) at $65{ }^{\circ} \mathrm{C}$ for $10 \mathrm{~min}$ and then slowly cooled $\left(\sim 1-2^{\circ} / \mathrm{min}\right)$ to $10^{\circ} \mathrm{C}$ to allow the formation of DNA duplexes. Oligonucleotides FWJ1 and FWJ4 were treated similarly. The two intermediate DNA products (duplexes) were mixed together, reheated to $65^{\circ} \mathrm{C}$, and again slowly brought down to $10{ }^{\circ} \mathrm{C}$. The formation of the four-way junction structure was monitored and confirmed by electrophoresis in a $10 \%$ 
nondenaturing acrylamide gel by comparing the respective electrophoretic mobility of the single-stranded oligonucleotides, the intermediate duplexes (FWJ2-FWJ3 and FWJ1FWJ4), and the completed four-way junction, as described by Panyutin et al. (23). On the basis of the measured intensity of SYBR green staining, we estimated that $90 \%$ of the singlestranded oligonucleotides were incorporated into four-way junctions (data not shown).

Sir3p-Nucleic Acid Electrophoretic Mobility Shift Assays (EMSA). Sir3p titrations of DNA templates were performed using electrophoretic mobility shift assays. A given quantity of Sir3 protein was mixed with the DNA template and equilibrated at $25^{\circ} \mathrm{C}$ for $30 \mathrm{~min}$. The EMSA were performed using DNA at either 5 or $10 \mathrm{ng} / \mu \mathrm{L}$. The experiments were compared using the same values of Sir3p molar ratios $\left(r^{\mathrm{Sir}}\right.$, corresponding to moles of Sir3 per moles of 208 bp DNA, as defined in Georgel et al. (7)). Aliquots ( $10 \mu \mathrm{L}$ for normal EMSA or $20 \mu \mathrm{L}$ in competition assays) of the equilibrated solutions containing different amounts of Sir $3 p$ were loaded onto $1 \%$ agarose gels (longer fragments: $\sim 200 \mathrm{bp}$ and above) or 6\% acrylamide (shorter DNA fragments: $12-100 \mathrm{bp}$ and single-stranded DNA) for quantification of the free DNA template band by integration of the Southern blot signal intensities (using NIH ImageJ). In each quantified gel, control lanes containing DNA with no added Sir3 were loaded and coelectrophoresed in order to provide internal calibration standards, which also provided an estimate of the standard deviation of measured free DNA values.

Electron Microscopy. Samples were prepared for transmission electron microscopy essentially as described (12). Briefly, DNA and Sir3p were mixed at the desired concentrations in HEN buffer (10 mM Hepes, $0.25 \mathrm{mM}$ EDTA, and $2.5 \mathrm{mM} \mathrm{NaCl}$ ), held at room temperature for $30 \mathrm{~min}$, and then fixed with $0.1 \%$ glutaraldehyde for $4 \mathrm{~h}$ at $4{ }^{\circ} \mathrm{C}$ before overnight dialysis into HEN. Samples were diluted, applied to glow-discharged carbon-coated grids, and positively stained with $1 \%$ aqueous uranyl acetate followed by extensive washing. Grids were examined in a Tecnai 12 TEM operated at $100 \mathrm{kV}$ in the tilted darkfield mode, and digital images were recorded using a TVIPS $2024 \times 2024$ CCD camera.

Analysis of Binding Curves. Binding analyses typically refer to measurements of the amount of bound complex formed as a function of increasing concentration of ligand. However, for a variety of reasons, protein-DNA complexes often cannot be unequivocally identified and quantified directly from gel retention assays. The free template concentration, $m$, is more easily estimated and is directly related to the chemical potential of the DNA template in the equilibrium solution (22). A classical approach to the formulation of multiple binding equilibria is through the binding polynomial or binding partition function, $P$, which is a function of all relevant protein-binding reactions to the template $(24,25)$. For a nonaggregating system, the chemical potential, $\mu_{\mathrm{M}}$, is related to the binding polynomial by the relation:

$$
\mu_{\mathrm{M}}=\mu_{\mathrm{M}}{ }^{\mathrm{o}}-R T \ln P(x)
$$

in which $\mu_{\mathrm{M}}{ }^{\circ}$ is the chemical potential under reference state conditions (here defined in the absence of ligand) and $x$ is the Sir3p ligand concentration. The concentration of free
DNA template, $m$, relative to the total concentration, $m_{\text {tot }}$, is obtained by

$$
m / m_{\mathrm{tot}}=1 / P(x)
$$

For a system in which concentrations are low enough for activity coefficient effects to be neglected, $P(x)$ is simply a sum of terms, each representing the concentration of a DNA species (bound by zero or more Sir3p ligands) relative to the unbound DNA template concentration. (The simplest example is a single-site binding model, or $P=([\mathrm{M}]+$ $[\mathrm{MX}] / /[\mathrm{M}]=1+k x$, where $k$ is the affinity constant in $\mathrm{M}^{-1}$.) Several binding polynomials $(P)$ representing different binding models were formulated following standard procedures (e.g., refs 25 and 26) and tested against the gel-retention assay data.

$$
\begin{aligned}
& \text { independent sites: } P_{1}=(1+k x)^{n} \\
& \text { sites interacting in pairs: } P_{2}=\left(1+2 k x+\delta k^{2} x^{2}\right)^{n / 2} \\
& \text { perfectly cooperative model: } P_{\mathrm{n}}=1+k^{n} x^{n} \\
& \text { nearest-neighbor model: } \quad P_{\mathrm{nn}}=(1,1) A^{n}(1,0)^{\prime}
\end{aligned}
$$

In these equations $k$ represents the intrinsic site affinity (units of $\mathrm{M}^{-1}$ ), the dimensionless parameter $\delta$ gives the multiplicative increase in affinity due to cooperative interaction with another bound site, $n$ represents the number of Sir3p binding sites on the template, and $A$ is a $2 \times 2$ transfer matrix with the top row $(1,1)$ and the bottom row $(k x, \delta k x)$.

Given $x_{\text {tot }}$ and $m_{\mathrm{tot}}$, the total concentrations of Sir3p and DNA template, respectively, the free concentration of Sir3 in the equilibrium solution was obtained by solving the massbalance equation: the total Sir3 concentration is written as the sum of the free and bound Sir3, the latter being expressed in general form by a logarithmic derivative of the binding polynomial (26), giving

$$
x_{\mathrm{tot}}=x+(\mathrm{d} \ln P(x) / \mathrm{d} \ln x) m_{\mathrm{tot}}
$$

Equation 4 implicitly defines the free Sir3p concentration, $x$, as a function of the total Sir3p and DNA concentrations and the other binding parameters contained in $P(x)$. A bisection algorithm was used to obtain $x$ at each total Sir3p concentration. Binding parameters were determined by fitting the free DNA template fraction (eq 2) versus total Sir3p concentration using the Marquardt algorithm for the different models for $P(x)$ given in eqs 3 .

\section{RESULTS}

We have recently demonstrated that Sir3p can interact directly with long dsDNA ( $\sim 2500 \mathrm{bp})$ and that the DNA component(s) of chromatin contribute(s) to its recruitment $(7,9)$. As previous studies have strongly suggested that Sir3p does not display any significant DNA sequence specificity (27-29), we focused our attention on binding as a function of DNA conformation and size. To further characterize the contribution of the DNA component of chromatin, we performed numerous EMSA and electron microsocopy (EM) imaging experiments to precisely assess the effect of DNA length and conformation, as well as Sir3p molarity, on binding and formation of higher order complexes. 


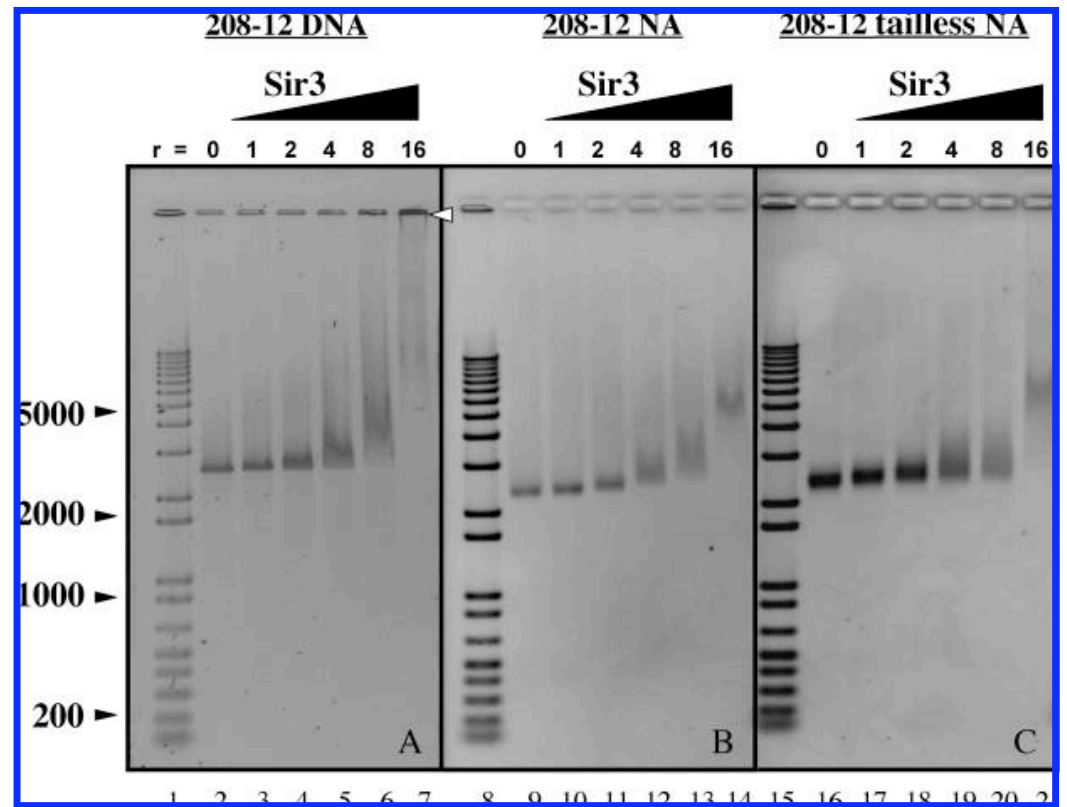

FIGURE 1: Sir3p binding efficiency to DNA is similar to that of tailless NA. (A) Binding of Sir3p to 208-12 DNA. Lane 1 contains the 1 $\mathrm{kb}+$ DNA marker. Lane 2 corresponds to 208-12 DNA alone. Lanes 3-7 are binding of Sir3p to 208-12 DNA at increasing $r^{\text {Sir3 }}$ ratios (from 1 to $16 \mathrm{Sir} 3$ per $208 \mathrm{bp}$ of DNA). The white arrowhead (lane 7) indicates the position of supramolecular complexes. (B) Binding of Sir3p to 208-12 NA. As described above lane 8 contains the $1 \mathrm{~kb}+$ DNA marker and lane 9 is NA alone. Lanes 10-14 correspond to NA in the presence of increasing $r^{\text {ir3 }}$ ratios. (C) Binding of Sir3p to 208-12 tailless NA. Trypsinized arrays were used as templates. Lane 15: $1 \mathrm{~kb}+$ DNA marker. Lane 16: NA tailless alone. Lanes $17-21$ correspond to NA in the presence of increasing $r^{\text {Sir3 }}$ ratios. All EMSA were performed under high DNA concentration $(10 \mathrm{ng} / \mu \mathrm{L})$.

Binding Ability of Sir3p to DNA and NAs. As controls, the binding of Sir3p to 208-12 normal and tailless nucleosomal arrays (NA) and parent 208-12 DNA was confirmed by EMSA under previously described conditions (7). The results indicated that Sir3p appears to bind cooperatively to the DNA template (Figure 1). We also noted that the lack of histone tails does not appear to impede Sir3p binding to nucleosomal arrays (compare Figure 1, panels B and C, lanes 11-14 and lanes 18-21). As the molar ratio of Sir3p was increased, we observed the formation of very large DNASir3p complexes, represented by material that did not migrate very far from the wells (see white arrowhead in Figure 1, panel A, lane 7). Under this set of experimental conditions ( $50 \mathrm{ng}$ of DNA in a final volume of $10 \mu \mathrm{L}$ ), the phenomenon was observed only with the 208-12 DNA template. This observation confirms the formation of the previously described Sir3p-associated supramolecular complexes (7).

Length Dependence: Sir3p Binds Differently to DNA Fragments Shorter than $208 \mathrm{bp}$. To test Sir3p binding as a function of DNA length in a context relevant to chromatin, we first monitored Sir3 binding activity to fragments that could accommodate 1, 7, and 12 nucleosomes. As we increased the size of the DNA from 208 bp using single unit or tandemly repeated copies of the 208 bp 5S rDNA from L. variegatus (15) (Figure 2A, panel A) to 1456 bp (7 repeats of 208 bp DNA, Figure 2A, panel B) and 2496 bp (12 repeats of 208 bp DNA, Figure 2A, panel C), we did not observe any significant difference in binding behavior. Sir3p molar ratios $\left(r^{\mathrm{Sir} 3}\right.$, normalized to $208 \mathrm{bp}$ ) from 1 to 16 were tested. At $r^{\text {ir3 }}$ from 4 to 16 , the Sir3p-DNA complexes that form are heterogeneous as seen by the presence of a smear (see Figure 2A, panels A-C, lanes 4-6). Based on the determination of free DNA half-depletion for each DNA length, no significant difference was observed as a function of the DNA size, suggesting that the actual number of $5 \mathrm{~S}$ rDNA repeats does not play a critical role in Sir3p binding. Interestingly, as the molar ratio is increased, the Sir3p-DNA complexes become too large to migrate significantly in the $1 \%$ agarose gels (as seen by accumulation of material in the wells). In conclusion, the Sir3p affinity for DNA fragments in the size range from 208 to 2496 bp did not appear to vary significantly.

Our initial results indicated that Sir3p binding to NAs leaves the linker DNA highly accessible for restriction enzyme cleavage (7), although more recent studies have suggested a possible role for linker DNA in Sir3p binding (9). To further investigate this issue and to determine the minimal length requirement for Sir3p binding, we performed additional EMSA experiments with DNA fragments ranging from 12 to $100 \mathrm{bp}$ (Figure 2B). Note that agarose gels did not give a sufficient resolution and that we switched to an acrylamide system to investigate the formation of Sir3p-DNA complexes. Sir3p was added to the DNA at $r^{\mathrm{Sir} 3}$ ranging from 1 to 8 . In all cases, Sir3p binding was very efficient, even at $r^{\mathrm{Sir} 3}$ of 1 to 2 (Figure 2B, lanes 3 and 4 for each panel). Higher molecular weight complexes were observed (as indicated by accumulation of material close to the wells; see open triangles in Figure 2B) for all DNA templates. Welldefined complexes were observed with DNA fragments of 32 and $12 \mathrm{bp}$ at $r^{\mathrm{Sir} 3}$ of 1 to 4 . When the $r^{\mathrm{Sir} 3}$ was increased to 8 , additional bands (Figure 2B, black triangles) corresponding to higher molecular weights were present, suggesting oligomerization of the initial Sir3p-DNA complexes. Combining this observation with earlier results using 20812 DNA or NA (7) leads to a model describing large supramolecular complexes involving trans interactions between individual DNA or NA molecules. These observations are consistent with a role for short linear stretches of linker DNA in Sir3p-chromatin fiber interactions. 


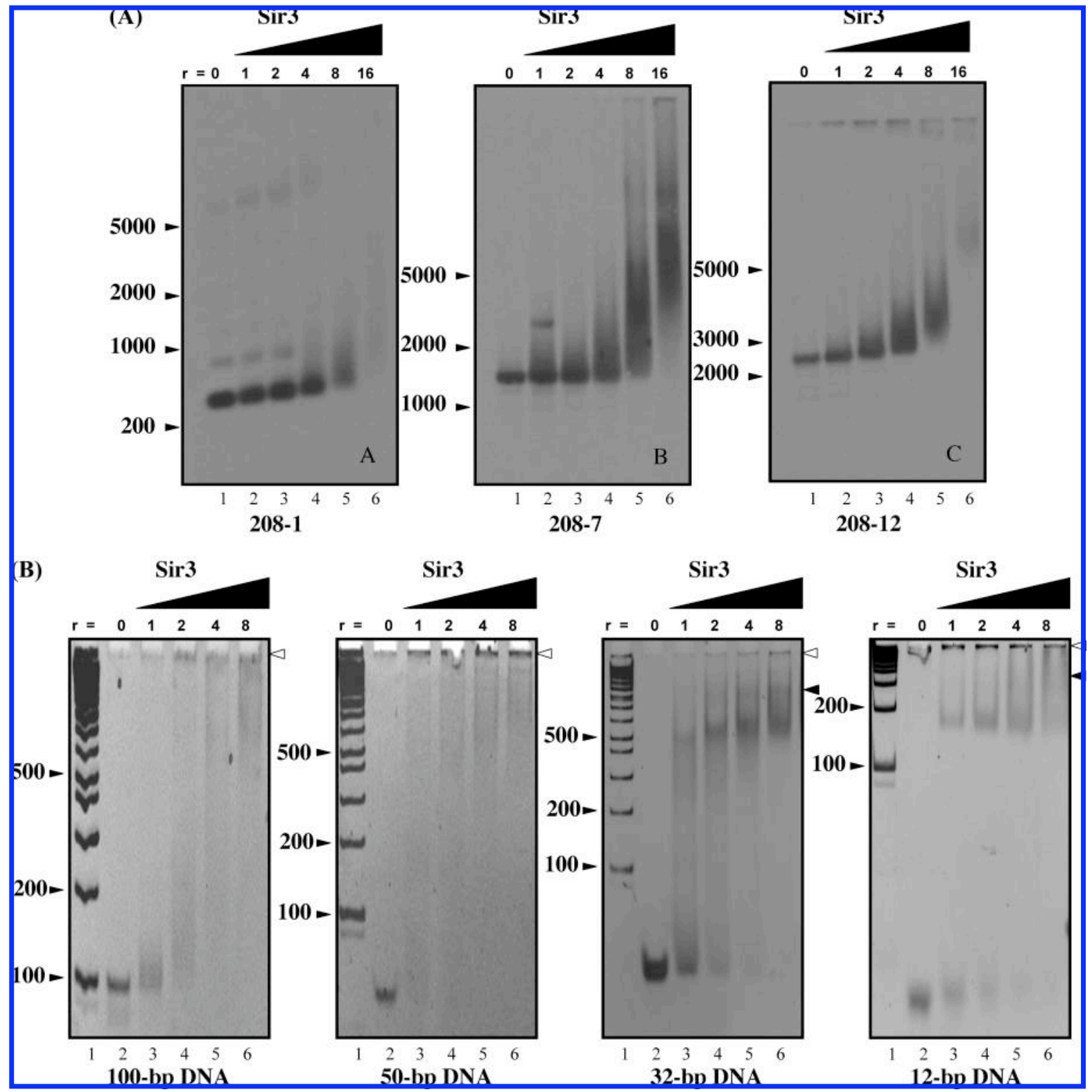

FIGURE 2: (A) Binding of Sir3p as a function of DNA length. Panel A: Binding of Sir3p to 208-1 DNA. Lane 1 corresponds to 208-1 DNA alone. Lanes 2-6 correspond to 208-1 DNA in the presence of increasing $r^{\text {Sir3 }}$ ratios (from 1 to 16 Sir3p per 208 bp of DNA). The location of DNA marker fragments is indicated on the left side of each panel. Panel B: Binding of Sir3p to 208-7 DNA. Lane 1: 208-7 DNA fragment alone. Lanes 2-6, similarly to panel A, are 208-7 DNA in the presence of increasing $r{ }^{\mathrm{Sir} 3}$ ratios (from 1 to 16). Panel C: Binding of Sir3p to 208-12 DNA. Lane 1: 208-12 DNA alone. Lanes 2-6: 208-7 DNA in the presence of increasing $r^{\text {Sir3 }}$ ratios (from 1 to 16). (B) Binding of Sir3p to short DNA fragments. Side by side comparison of Sir3p binding ability to DNA of size ranging from 100 bp down to $12 \mathrm{bp}$. The DNA and Sir3p-DNA complexes were separated using a native 6\% acrylamide gel. Lane 1 in each panel contains the $1 \mathrm{~kb}+$ DNA marker. Lanes 2 correspond to DNA alone. Lanes 3-6 contain DNA in the presence of increasing $r^{\mathrm{Sir} 3}$ ratios (from 1 to 8). The white arrowhead indicates the location of supramolecular complexes (close to the well). The black arrowheads indicate the formation of an intermediate size complex (32 bp DNA and 12 bp DNA panels). The sizes of relevant DNA bands are indicated on the left of each panel.

DNA Sequence/Conformation Dependence on Sir3p Binding. Our experiments indicate that both nucleosomal and DNA components may be involved in Sir3p-chromatin interactions (ref 30; see above). We were therefore interested in whether Sir3p showed a preference for DNAs with different conformations. Specifically, linker DNA may have a more linear conformation, where nucleosomal DNA would display a more curved or bent conformation. Based on the nucleosome core particle structure (8), nucleosomal DNA is distorted at positions 45 and 100 (positions nearly opposite the nucleosomal dyad axis), showing a more pronounced bending. The rest of the nucleosomal DNA is more gently curved around the histone octamer. To mimic all possible
DNA conformations described for the nucleosome core particle, we tested three different DNA fragments that would represent (1) the linker DNA as a linear/straight fragment (221 bp covering positions -185 to +36 from the hsp70 Drosophila melanogaster promoter region, which displays a nearly straight conformation), hereafter referred to as "straight", (2) the more pronounced bends described over the nucleosomal DNA at positions 45 and 100 mimicked using a template containing a sharper bend (a 199 bp fragment covering the binding site for RNA polymerase 1 from A. histolitica (22), referred to as "bent", and (3) the more evenly curved nucleosomal DNA, using the known $5 \mathrm{~S}$ rDNA positioning sequence that contains two curves $(15,22)$, 


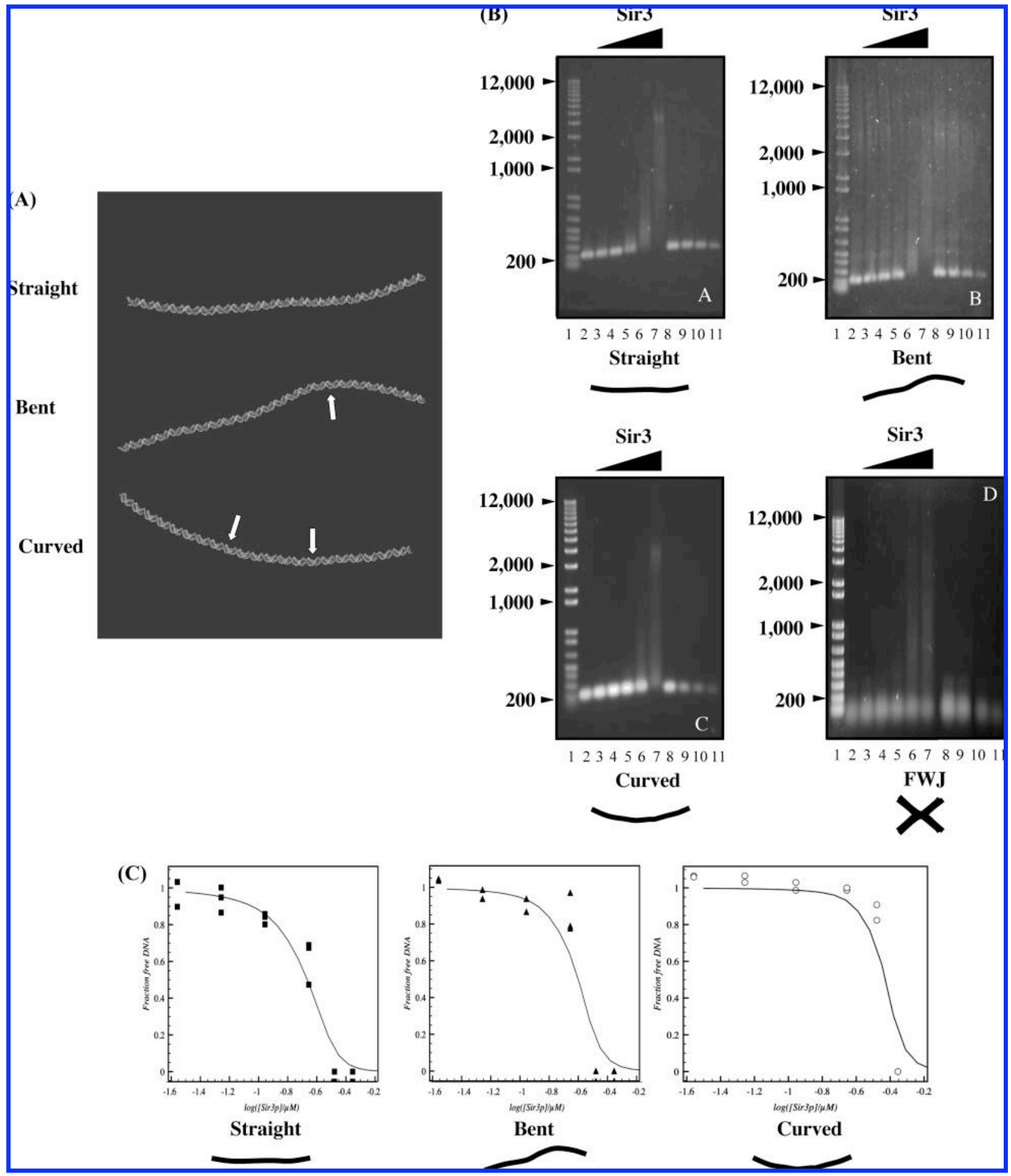

FIGURE 3: (A) Predicted curvature of the DNA fragments. The DNA sequences of all three fragments (p29-p58), PX199, and 208-1 were analyzed and visualized using the Trifonov algorithm (http:hydra.icgeb.trieste.it/ kristian/dna/). The presented orientations were selected to display the maximum curvature. The locations of the bends and curves are indicated by the white arrows. (B) EMSA analysis of Sir3p binding to various DNA conformations Panel A: Sir3p-mediated DNA depletion analysis using the "straight" DNA template. Lane 1 contains the $1 \mathrm{~kb}+$ DNA marker. Lane 2 contains the DNA template alone. Lanes 3-8 are the DNA templates in the presence of increasing $r^{\text {Sir3 }}$ (from 1 to 16). Lanes 8-11 contain a serial dilution of "straight" DNA used for calibration in the depletion analysis. Panel B: Similar experiment using the "bent" DNA as template. Panel C: Similar experiment using the "curved" DNA as template. The sizes of relevant DNA bands are indicated on the left of each panel. (C) Fraction of free DNA for increasing concentrations of Sir3 protein. Left: "straight" template (Hsp). Middle: "bent" template (Pol1). Right: "curved" template (208-1). Estimated total Sir3 concentrations at $1 / 2$ DNA depletion are $0.24,0.28$, and $0.40 \mu \mathrm{M}$, respectively.

referred to as "curved". The actual conformation of all three fragments was modeled using an algorithm developed by Trifonov (ref 31, http://hydra.icgeb.trieste.it/ kristian/dna/, Figure 3A). In Figure 3A, all fragments are represented in an orientation that reflects the maximum predicted curvature. To confirm the predicted DNA conformation differences, we performed QAGE analysis (in triplicate) of the various fragments to determine their electrophoretic effective radii. 
Table 1: Characterization of Mobility and Sir3 Binding of the DNA Fragments

\begin{tabular}{llll}
\hline & \multicolumn{1}{c}{ straight } & \multicolumn{1}{c}{ bent } & \multicolumn{1}{c}{ curved } \\
\hline size $(\mathrm{bp})$ & 221 & 199 & 208 \\
$R_{\mathrm{e}}(\mathrm{nm})$ & $11.18 \pm 0.6$ & $10.37 \pm 0.46$ & $9.73 \pm 0.3$ \\
$k\left(\mathrm{M}^{-1}\right)$ & $1.4( \pm 0.2) \times 10^{5}$ & $6.2( \pm 0.2) \times 10^{4}$ & $1.36( \pm 0.02) \times 10^{4}$ \\
$\log (\delta)$ & $1.62( \pm 0.09)$ & $1.98( \pm 0.01)$ & $2.44( \pm 0.003)$ \\
$n$ & $4.4( \pm 1.9)$ & $4.5( \pm 0.5)$ & $5.0( \pm 0.4)$ \\
\hline
\end{tabular}

If the conformation of all fragments was assumed to be linear, then based on size only, the order of $R_{\mathrm{e}}$ would have been: "straight", "curved", followed by "bent". However, our results (see Table 1) indicate a conformational component that confirms the predictions from the Trifonov modeling algorithm for the various DNA fragments. The smallest $R_{\mathrm{e}}$ was that of the "curved" fragment $(9.7 \pm 0.3 \mathrm{~nm})$, and the largest was that of the "straight" DNA (11.18 $\pm 0.6 \mathrm{~nm})$. The "bent" DNA fragment had a value between those of the other two fragments $(10.37 \pm 0.46 \mathrm{~nm})$. All three fragments were subjected to EMSA analysis under the lower concentration $(5 \mathrm{ng} / \mu \mathrm{L})$ conditions described for Figures 1 and 2. EMSA experiments employed a fixed mass of DNA (50 ng) that was incubated in the presence of increasing $r^{\mathrm{Sir} 3}$. Comparison of half-depletion of free DNA in each panel (Figure 3B, panels $\mathrm{A}-\mathrm{C}$, lanes 7 and $8 ; r^{\mathrm{Sir} 3}$ of 8 to 16 , Figure 3C) showed the "straight" fragment to be the template with highest Sir3p binding efficiency and the "curved" fragment (5S rDNA 208-1) to have the lowest binding efficiency. The difference in binding EMSA shifts between the three fragments was very small. To confirm this result, we performed a competition assay mixing all three fragments in equimolar amounts with increasing $r^{\mathrm{Sir} 3}$. The order of shifting as seen by EMSA matched the expected binding ability seen when using individual fragments (data not shown).

The binding of Sir3p to short DNA stretches left open the possibility that the protein could interact with the nucleosomal entry-exit DNA. A four-way junction (FWJ) DNA template, commonly used as a substitute for the nucleosomal DNA entry-exit region, was assembled and used as a template (23). The binding affinity of Sir3p for the FWJ, based on half-depletion of free DNA, was significantly lower than that of any of the tested linear fragments (compare Figure 3B, panel D, lanes 6 and 7, to Figure 3B, panels A-C, lanes 6 and 7). This result suggests that Sir3p's ability to bind to the nucleosome entry-exit region is low. It is important to note that, depending on $\mathrm{Mg}^{2+}$ and EDTA concentrations, FWJ can adopt a partially flattened conformation that may interfere with Sir3p binding $(32,33)$. This potential conformational change may have affected Sir3p binding resulting in the observed low affinity. All three linear DNA fragments' binding properties were tested by EMSA and modeled; the results are summarized in Table 1.

Sir3p Binding to DNA Is Highly Cooperative. The analysis of Sir3p-DNA binding indicates that it is strongly cooperative. To determine the mode of interaction over a wide range of $r^{\mathrm{Sir} 3}$, the 208-1 monomeric unit of the tandemly repeated 208-7 and 208-12 DNA was selected to establish a cooperative binding baseline for Sir3p. It was mixed in the presence of increasing $r^{\mathrm{Sir} 3}$, and free DNA depletion was then determined from gels as a function of the total Sir3p concentration (expressed in micromolar) and analyzed using eq 2. The data, run in triplicate, provided a measure of the intrinsic run-to-run variability of $0.1-0.15$ in units of fractional template concentration. The tendency of the free DNA to disappear completely after a few steps of the titration with Sir3p was clearly seen in each experiment.

In order to determine how cooperatively Sir3 was binding, we tested several different binding models using free DNA depletion data for the 208-1 template and for the "straight" and "bent" DNA templates. We first applied a noncooperative independent-sites model (eq 3a) with a single class of binding sites. The results of this binding model were very poor: the standard error of a point of the best fit varied from 0.20 to 0.27 depending on the template, and the noncooperative model was clearly unable to account for the steepness of the free template depletion curve. It bears pointing out that inclusion of additional classes of independent binding sites would have exacerbated the poor fit, leading to apparent anticooperativity and consequently an even less steep curve (24). Adding a cooperative interaction for pairs of interacting Sir3 binding sites (eq 3b) improved the fit somewhat, but the standard error of a point of the resulting best fit $(0.14-0.23)$ was still far larger than the intrinsic errors associated with the data.

We found that models best representing the free DNA depletion data involved a high degree of cooperativity in Sir3p binding to the template. The high cooperativity was first modeled as a phenomenological "all-or-nothing", or perfectly cooperative, association (eq 3c). This simple model accounted well for the steepness of the template depletion curves and provided standard errors of $0.1-0.15$, well within in the range of the intrinsic run-to-run variability of the data. Another cooperative model that has the additional benefit of being immediately applicable to template DNA of any length is the nearest-neighbor model (eq 3d). This model described the data with the same standard error of a point as the perfect cooperativity model. Although gel data are not of sufficiently high precision to distinguish between details of the cooperative model chosen to represent the Sir3p interaction, the binding results clearly suggest a high degree of cooperativity in their binding to the naked DNA template. The fits to the data are shown in Figure 3C. Intrinsic association constants obtained for Sir3p binding to the different templates ("straight", bent", and "curved") using this model are shown in Table 1. All templates show a similar number of binding sites for Sir3. Binding to the straight DNA is favored by a factor of 10 over the curved template, although the cooperative interaction is highest for the curved DNA.

We also used EMSA to examine Sir3 binding to DNA templates containing 7 or 12 repeats of the $208 \mathrm{bp}$ sequence. The free DNA depletion data for the 208-1, 208-7, and 20812 templates are shown in Figure 4. As with the 208-1 data alone, the 208-7 and 208-12 template data are clearly consistent with cooperative Sir3p binding: a noncooperative binding model again resulted in a very poor fit. In order to analyze these data obtained for templates of significantly different lengths, the nearest-neighbor interaction model was used (eq 3d). This formulation is more physical than the perfect cooperativity approach and models the cooperativity as arising from stabilizing interactions between Sir3p molecules bound at neighboring sites on the DNA template. This model also described the cooperative Sir3p binding quite 


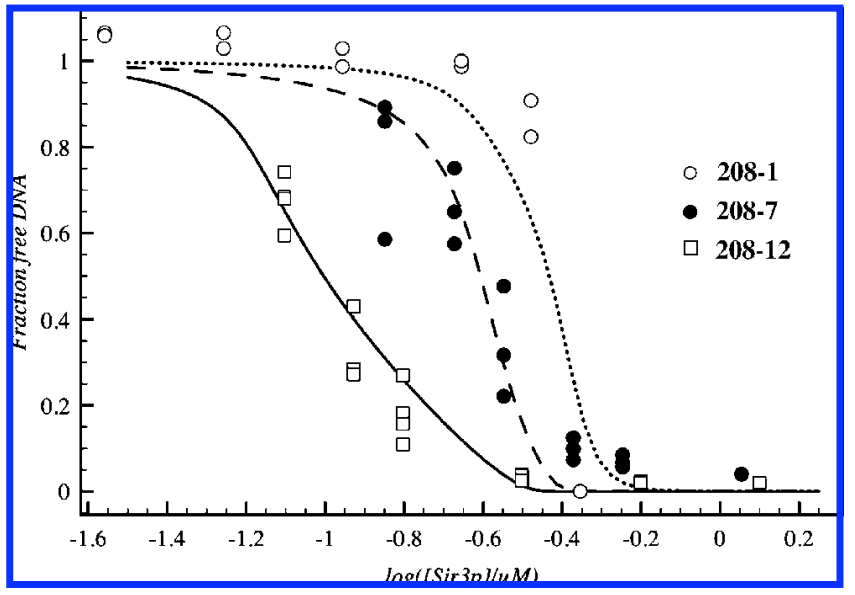

FIGURE 4: Sir3p binds cooperatively to DNA. Fraction free/total DNA template plotted as a function of the logarithm of the total Sir3p concentration for the 208-1 (open circles), 208-7 (filled circles), and 208-12 (white squares) templates. Corresponding lines (dotted, broken, and solid, respectively) indicate the best fit of the nearest-neighbor model (eq 3d, best-fit SEP 0.10) with binding site size of $28 \pm 2 \mathrm{bp}$ (calculated by template length in $\mathrm{bp} / \mathrm{n}$ ), intrinsic binding constant $\log \left(k / 1 \mu \mathrm{M}^{-1}\right)=-1.88 \pm 0.03$ for the $208-1$ template and $-2.09 \pm 0.02$ for the 7 - and 12-mers, and nearestneighbor interaction term $\log (\delta)=2.47 \pm 0.04,2.66 \pm 0.03$, and $3.22 \pm 0.08$ for the $208-1,-7$, and -12 templates, respectively.

well: the curves shown in Figure 4 correspond to the best fit of this model to all data sets simultaneously, in which the total number of sites was defined to be 1,7 , or 12 times the 208-1 template value. Fitted parameters are given in the legend of the figure. Another way of illustrating the positive cooperativity in Sir3p binding is in terms of the dissociation constant or the inverse of the affinity constant. Intrinsic Sir3p dissociation constants are on the order of $100 \mu \mathrm{M}$, referring to binding of a Sir3 protein to a site on the DNA with no Sir3 bound to adjacent sites. In contrast, the effective dissociation constant at a site neighboring a bound Sir3 protein will be on the order of $0.1 \mu \mathrm{M}$. The affinity increase, given by the parameter $\delta$, is a few hundred to a thousandfold for all $208 \mathrm{bp}$ repeat templates.

The formation of 208-12 DNA-Sir3 complexes and cooperativity were further investigated by EM imaging (Figure 5, panel D) to evaluate stoichiometry and conformation. Cooperative binding seemed to be favored under the high DNA and high Sir3p concentration conditions, suggesting a Sir3p-Sir3p interaction component driven by high local concentration. The different complexes observed by EMSA were imaged at various $r^{\mathrm{Sir} 3}$. At low $r^{\mathrm{Sir} 3}$ and low DNA concentration, cooperative binding is evidenced by the coexistence in the same sample of free DNA fragments (Figure 5D, panel A) and Sir3p clusters on the DNA (panels C, D). As the $r^{\mathrm{Sir} 3}$ is increased to 8 and 16 and under high DNA concentration conditions, the DNA becomes coated with Sir3 clusters (Figure 5, panels E and F) and eventually forms self-associating DNA-Sir3p complexes (Figure 5, panels $\mathrm{G}$ and $\mathrm{H}$ ). Once again, the cooperative nature of the event is evidenced by the presence of Sir3-free DNA molecules adjacent to Sir3p-associated DNA complexes (Figure 5, panels D and G).

Sir3p Saturation Affects Complex Formation. On the basis of our observation linking the formation of higher order Sir $3 p-D N A$ complexes with the actual DNA concentration, we decided to systematically evaluate its effect on the initial
Sir3p binding, as well as on the formation of supramolecular complexes. EMSA experiments were performed using the same three previously described DNA, NA, and tailless NA templates under higher DNA concentrations over the same range of Sir3p molar ratios. The relative binding affinity observed under $5 \mathrm{ng} / \mu \mathrm{L}$ DNA concentration conditions reflected the initial results obtained and described in Figures $1 \mathrm{C}$ and $4 \mathrm{~A}-\mathrm{C}$. The connection between the formation of supramolecular complexes through DNA and Sir3p interactions was investigated using $10 \mathrm{ng} / \mu \mathrm{L}$ DNA (Figure 6A, lanes 13 and 14; see white arrowhead). No large complexes (running close to wells in agarose gels) were observed under $10 \mathrm{ng} / \mu \mathrm{L}$ DNA conditions with either the NA or tailless NA (Figure 6A-C, lanes 6-7 and 13-14). Further, we observed the formation of a well-defined complex and the depletion of free template at a lower $r^{\text {Sir3p }}$ under $10 \mathrm{ng} / \mu \mathrm{L}$ DNA experimental conditions for NA, tailless NA, and naked DNA (Figures 6A-C; compare lanes 6 and 7 to lanes 13 and 14). The later depletion of free material and the early formation of complexes of intermediate size between Sir3p and tailless NA suggest a role for the histone N-termini, possibly through electrostatic interactions resulting in a partial masking of the DNA. The results indicated a strong connection between local Sir3p concentration and DNA binding efficiency. This suggests that the local Sir3p concentration may contribute to the formation of complexes involved in silencing in a DNA-dependent manner.

Sir3p Interaction with Single-Stranded DNA. After observing that Sir3p can bind to short dsDNA fragments, we investigated whether it can also complex with single-stranded DNA (ssDNA). The primer p7 (32-mer) was used as template for Sir3p EMSA analysis (Figure 7). The 32-mer ssDNA complexed with Sir3p even at a ratio of one Sir3p molecule per DNA molecule and was nearly entirely depleted at a $r^{\text {ir } 3}$ of 4 (Figure 7, lane 5). Multiple complexes of higher molecular weight were formed as the $r^{\mathrm{Sir} 3}$ was increased, indicating either multiple binding sites or the formation of Sir3-DNA oligomers. At $r^{\mathrm{Sir} 3}$ of 4 and 8 (Figure 7, lanes 5 and 6), the complexes generated were too large to be resolved in the gel, and some of the material remained trapped next to the well area.

\section{DISCUSSION}

The ability of Sir3 to contribute to the general silencing mechanism is well-established (2-4). The development of silenced regions over the HM loci and telomeres has been linked to Sir3p interactions with hypoacetylated histone H3 and $\mathrm{H} 4 \mathrm{~N}$-termini $(1-3)$, but despite initial studies $(5,10)$ the mechanism of spreading along chromatin fibers remains poorly explained. We have shown that the Sir $3 p$ interacts with both DNA and the nontail nucleosomal components of chromatin while establishing a condensed chromatin architecture. Our results presented here, as well as previously published work, strongly suggest that the DNA component may be important in the establishment of silenced regions. Sir3p-DNA interactions have previously been mentioned in the literature $(7,9)$, but no thorough analysis had been performed to investigate their actual contribution to silencing. The description of the DNA binding properties of Sir3p as cooperative and size-, conformation-, and DNA concentration-dependent opens the door for a more a thorough 


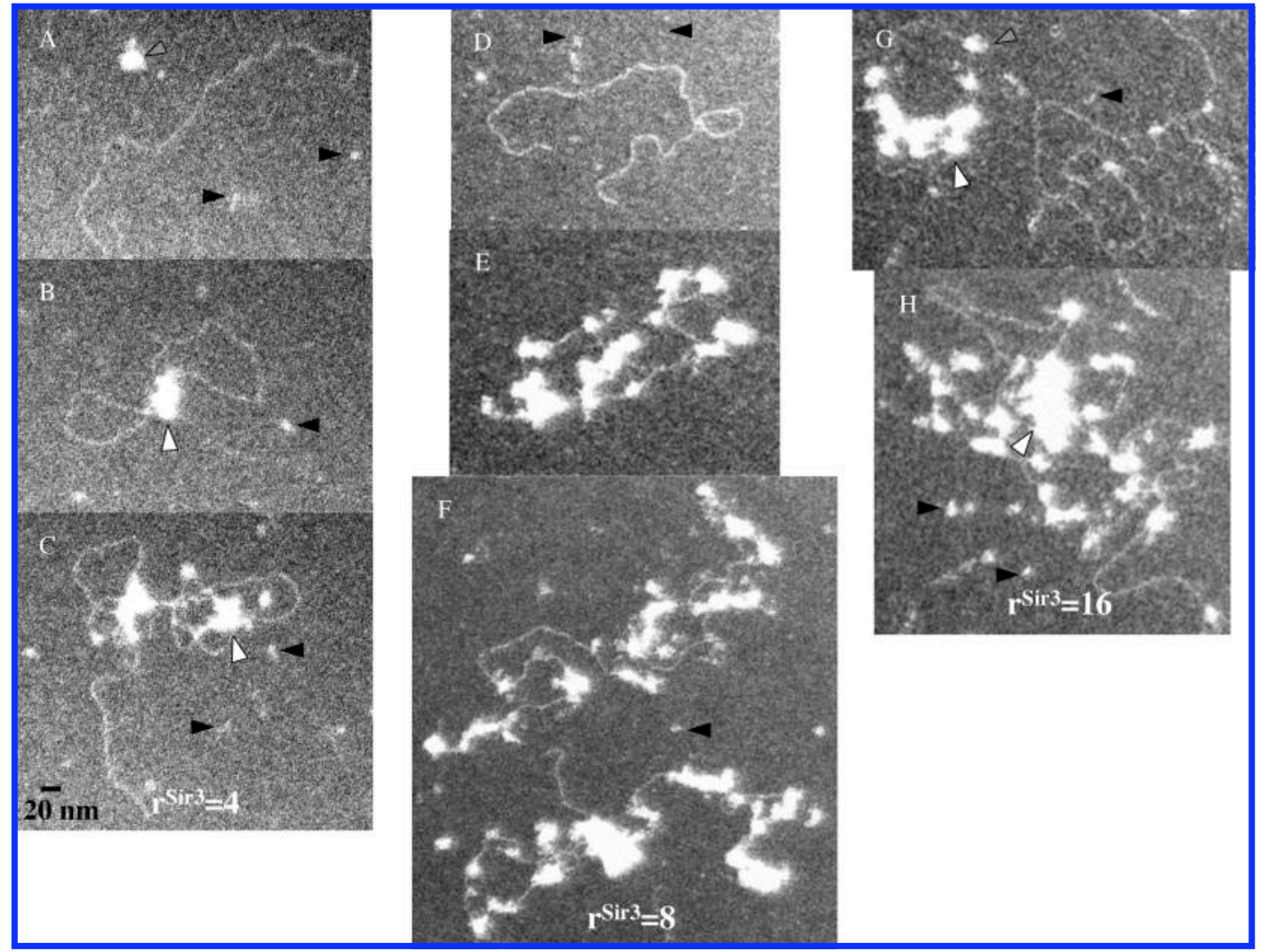

FIGURE 5: EM imaging of Sir3p-DNA complexes at low and high DNA concentrations. 208-12 DNA at a concentration of 5 ng/ $\mu$ L and $r^{\mathrm{Sir} 3}=4$ (panels A-C). Small (black arrow) and large oligomers of Sir3p (gray arrow) can be observed in the background in the presence of free DNA (panel A). The population also includes complexes with large Sir3p clusters bound to DNA (white arrow) and resulting in loops (panels B and C). The bar in panel C corresponds to $20 \mathrm{~nm}$. At higher $r^{\mathrm{Sir} 3}$ of 8 and high DNA concentration (panels D-F), free DNA can still be observed (panel D), in addition to molecules that are almost entirely covered by Si3p (panels E and F). Free Sir3p can still be observed (black arrows). At even higher $r^{\mathrm{Sir} 3}=16$, the Sir3p-coated DNA complexes appear to associate to form very large supramolecular assemblages (white arrows, panels $\mathrm{G}$ and $\mathrm{H}$ ). The coexistence of free DNA alongside the large assemblages (panel G) strongly supports the cooperative model.

understanding of the how Sir3p functions in the initiation and spreading of silencing.

Importance of Nucleosomal DNA Features for Sir3p Binding. Our Sir3p binding analysis indicates high affinity for naked DNA, cooperative binding at higher $r^{\text {Sir3p }}$, and, importantly, the influence of local Sir3p concentration, all of which support a model where initial Sir3p recruitment and spreading would consist of three separate steps. The initial recruitment of Sir3p to a chromatin or DNA template in vivo has been shown to involve Sir4p (3) and histone tail deacetylation by Sir2p (34), brought together through interactions with the $\mathrm{H} 3$ and $\mathrm{H} 4 \mathrm{~N}$-termini. The level of acetylation of histone $\mathrm{H} 3$ appears to be intricately linked to the regulation of the efficiency of the initial Sir3p mobilization and may contribute to its ability to spread (35). However, Hoppe and co-workers (36) recently presented evidence for an alternative mode of action that would involve Sir3p in spreading silencing in the absence of Sir2-Sir4 complexes (see also refs 4, 37, and 38). Following this line of evidence, one can envision a significant role for DNA in spreading of silencing that may not be dependent on histones $\mathrm{H} 3$ and $\mathrm{H} 4$.

Our observation that the binding of Sir3p to 208-12 5S rDNA displays a similar affinity to that of the same DNA reconstituted into nucleosomal arrays using tailless histones confirms that Sir3p plays a role in spreading silencing through DNA interactions (ref 7, Figure 1). Our analysis of DNA size dependence seems to indicate that DNA larger than 208 bp is a less efficient target than shorter fragments (down to $12 \mathrm{bp}$ ). This may include association with short linker DNA, if available for binding. This observation, combined with the ability of Sir3p to spread silencing in the absence of Sir $4 p$ and Sir2p, suggests a spreading mechanism involving short stretches of nucleosomal or linker DNA that would require minimal Sir3p interactions with core histones. Our analysis of DNA conformation indicates a Sir3p binding preference for short straight DNA fragments. At equal molar ratio, potential interactions between Sir3p and nucleosomal DNA could be mediated through recognition of short stretches of straight DNA. As was described by Luger et al. (8), the last $10 \mathrm{bp}$ segment at the edge of the nucleosome structure (close to the entry-exit location) is mostly straight and has limited interactions with the histone octamers and, thus, could provide Sir3 with a preferred DNA binding site. Another physical feature of the nucleosome core particle may also be of importance for Sir3p binding to DNA. The periodicity of histone tails passing through the DNA double helix at 20 bp intervals (8) may delineate structural domains that could be preferred targets for Sir3p binding. The $20 \mathrm{bp}$ interval is of the same order of magnitude as the minimal observed size that allows Sir3p binding (12 bp, as described in our size dependence binding analyses, Figure 2B). The observed differences in binding efficiency to linear DNA of $\sim 200$ bp in length are also consistent with such a mode of interaction. The mostly straight DNA was a slightly better 


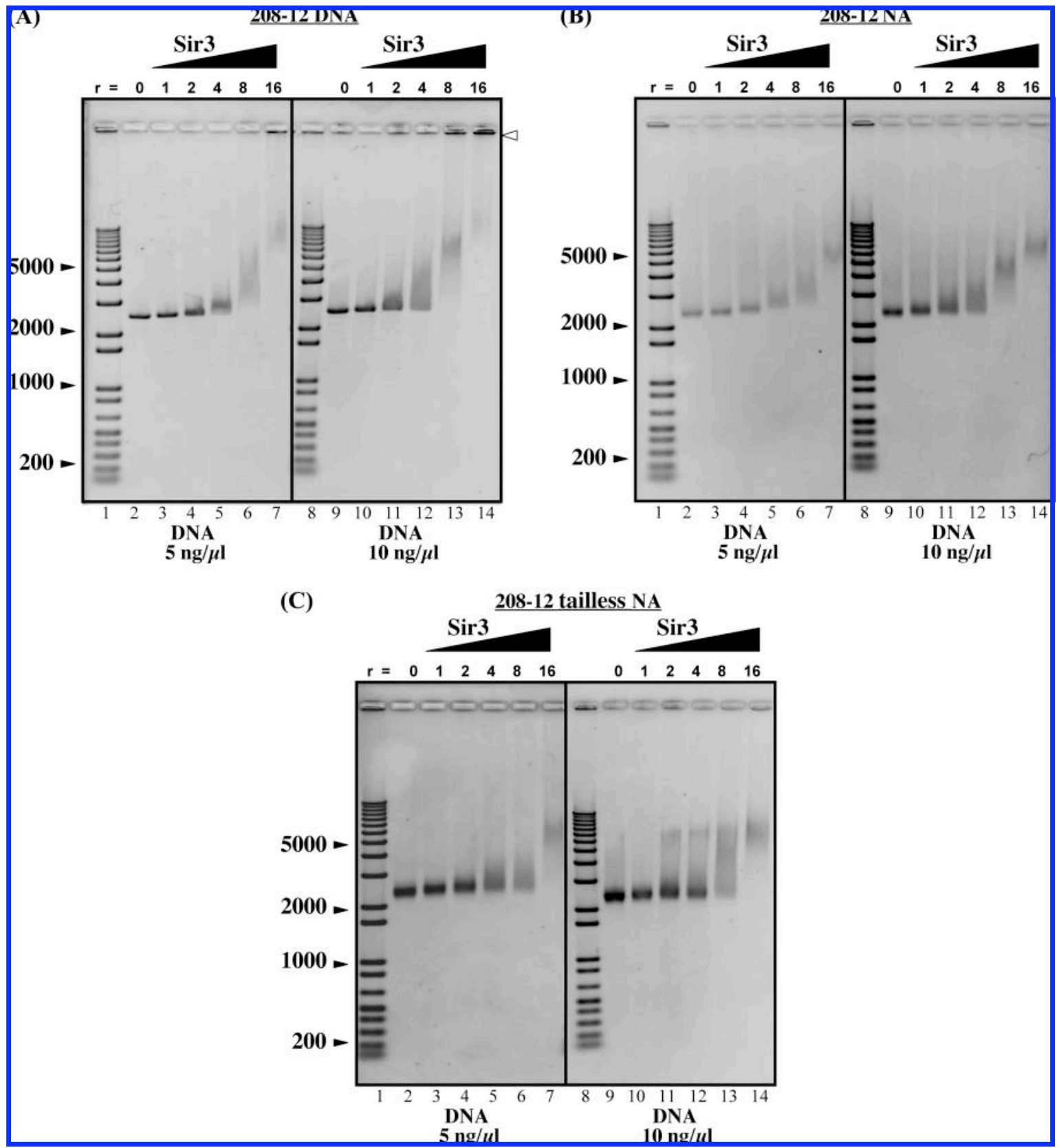

FIGURE 6: (A) Effect of DNA concentration of Sir3p binding. Side by side comparison of Sir3p binding ability at $5 \mathrm{ng} / \mu \mathrm{L}$ (left panel) and at $10 \mathrm{ng} / \mu \mathrm{L}$ (right panel). Lanes 1 and 8 contain the $1 \mathrm{~kb}+$ DNA marker. Lanes 2 and 9 correspond to DNA alone. Lanes 3-7 and 10-14 contain 208-12 DNA in the presence of increasing $r^{\operatorname{Sir} 3}$ ratios (from 1 to 16). The white arrowhead indicates the location of supramolecular complexes (7). (B) Effect of DNA concentration on Sir3p binding to nucleosomal arrays. The same experiment was repeated using NA instead of DNA. The gel setup is identical to that described in panel A. (C) Effect of DNA concentration on Sir3p binding to tailless nucleosomal arrays. The same experiment was repeated using tailless NA instead of DNA. The gel setup is identical to that described in panel A.

substrate for Sir3p binding, whereas the DNA with highest curvature interacted less efficiently. In the context of nucleosomal DNA, the highest curvature is observed at superhelical (SHL) positions 1.5 (15 bp from the DNA entry site) and 3.5 and 4 about $15 \mathrm{bp}$ from straighter DNA (around SHL position 5.5) having fewer histone contacts $(8,39,40)$. The DNA fragments we tested (Figure 3, panels A-C) reflect such differences in intrinsic or induced curvature. Our results suggest that Sir3p binding may be more efficient over straighter portions of the nucleosomal DNA. Since other proteins such as MENT (41) have been described as crosslinking nucleosomal DNA at the entry-exit region, we investigated Sir3p binding to a synthetic FWJ designed to mimic the nucleosomal linker entry-exit site. The poor binding of Sir3p to such templates does not support a binding mechanism similar to that of MENT or even linker histones (Figure 3, panel D 41, 42) but instead favors a model involving association with nucleosomal and/or linker DNA.

Cooperative Binding and Sir3p Local Concentration. Our results strongly suggest a cooperative binding mechanism for Sir3p to both DNA and NA (Figures 4 and 5). The binding mechanism that best described the EMSA-based data is the nearest-neighbor model (see Table 1). The presence in EM images of DNA entirely devoid of Sir3 proteins adjacent to templates with high Sir3 occupancy (Figure 5 D) at $r^{\mathrm{Sir} 3}$ ratios as high as 16 also strongly supports our 


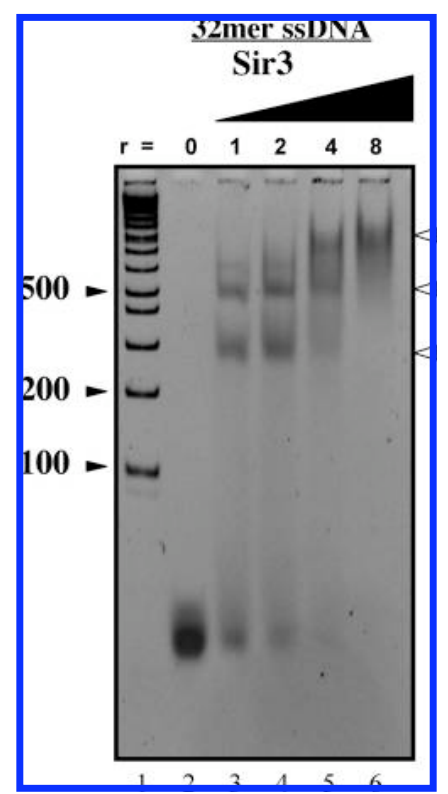

FIGURE 7: Sir3p binds to ssDNA. EMSA experiments were performed using 32-mer ssDNA (primer p7; see sequence in Experimental Procedures) under similar DNA concentration and $r^{\mathrm{Sir} 3}$ conditions to that shown in Figure 2B. Based on DNA depletion, Sir3p appears to bind short ssDNA as efficiently as short dsDNA forming complexes of various sizes (white arrows). Lane 1 contains $1 \mathrm{~kb}+$ DNA marker. Lane 2 contains ssDNA alone. Lanes 3-6 are ssDNA in the presence of increasing $r^{\mathrm{Sir} 3}$ (from 1 to 8 ).

EMSA analysis. Similar gel results for Sir3p have recently been reported (9). In addition to the observed cooperativity of Sir3p binding to DNA and NA, we observed that, at identical $r^{\mathrm{Sir} 3}$ ratios, the formation of $\mathrm{Sir} 3 \mathrm{p}-\mathrm{DNA}$ or Sir3p-NA complexes was highly dependent on the actual substrate molarity at which the experiments were performed (Figure 5A-C). Increases in local Sir3p concentration appear to favor cooperative recruitment of Sir3 molecules to the DNA and chromatin fibers, indicative of a novel mode of interactions leading to silencing. The formation of higher molecular weight (seen close to the well during EMSA experiments, Figure 5A, lanes 13 and 14, and ref 7), referred to as supramolecular complexes, was also shown to be highly dependent on molarity. The high $r^{\mathrm{Sir} 3}$ ratios combined with high molarity leads to the coating of DNA molecules and also contributes to the formation of assemblages of Sir3pcovered DNA (see Figure 5D, $r^{\mathrm{Sir} 3}=16$, at high molarity conditions). The combination of results obtained with DNA and tailless NA suggests a limited role for the histone tails in Sir3p spreading. The cooperative nature of Sir3p binding and the importance of local concentrations lead us toward a model where Sir3p silencing would be described as a threestep mechanism (Figure 8) that bears some similarities to the binding and recruitment of heterochromatin proteins 1 or HP1 $\alpha, \beta$, and $\gamma$, each playing a complementary role $(43,44)$. The initial recruitment of Sir3p would be dependent on interactions with nucleosomal features that involve binding to structurally specific DNA conformation features of the nucleosome core particle (see previous section). As the local concentration of Sir3p reaches a critical value, the cooperative mode of binding would favor Sir $3 p$ spreading from occupied sites using DNA as a track. The binding of Sir3p to DNA also appears to initially promote the formation of DNA loops (see Figure 5D, panels B and

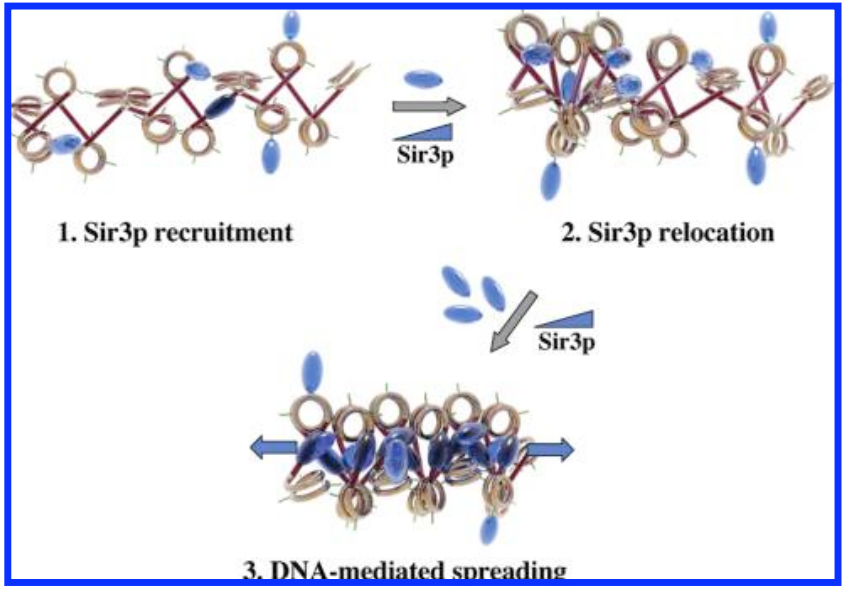

FIGURE 8: Model for the DNA-mediated Sir3p binding component. The model represents only the DNA portion of a chromatin fiber (the linker DNA is highlighted in red and the histone N-termini in green). The blue ovals represent Sir3p. The initial Sir3p recruiting step is mediated by nucleosomal domain interactions. As the local concentration increases (indicated by the blue triangle), additional Sir3p-DNA interactions stabilize the complex. Upon further increase in local concentration, Sir3p cooperative binding to DNA significantly contributes to the spreading of silencing along the chromatin fibers (as indicated by the diverging blue arrows).

C) that are reminiscent of the MENT-induced compaction of chromatin (45). This model is supported by evidence that Sir $3 p$ alone, when overexpressed in yeast, can account for repression observed at specific loci $(4,36,37)$. As the local concentration reaches its threshold, the Sir3p-coated DNA fiber would start to interact, probably through DNA-Sir3/ Sir3-DNA bridges. The actual role of the tails of histones $\mathrm{H} 3$ and $\mathrm{H} 4$ and their posttranslational modifications remain to be investigated. To further delineate the Sir3p domains responsible for spreading of silencing, we have also started a more thorough analysis of Sir3-DNA affinity using various Sir3p deletion constructs.

Sir3p Binding to Single-Stranded DNA. The binding of Sir3p to ssDNA may contribute to the establishment of functional telomeric complexes. Telomere silencing and telomere position effect (TPE) are both associated with the presence of Sir3p in subtelomeric DNA but are also regulated by the amount of ssDNA available (46). A specific class of single-stranded binding proteins, including Est1 (47), NSR1 (48), GBP2 (48), the yeast protein Rlf6p, and Chlamydomonas reinhardtii Gbp1 (49), has been described as binding single-stranded G-strand telomeric DNA, and it remains possible that Sir3p also plays a role in this process through its ssDNA binding activity. This mechanism may have similarities to that observed using truncated forms of Rap1 (49, 50). Konkel and colleagues have shown that Rlfp6p is required for the appropriate location of Rap1p, a mechanism that also involves $\operatorname{Sir} 3 p$ and $\operatorname{Sir} 4 p(1,50)$. A possible role for Sir3p, consistent with its ssDNA-binding activity, may include the stabilization of the Rlf6p-Rap1 complex (51). Alternatively, the single-stranded nucleic acid binding activity of Sir3p may be functionality related to that of DDP1, a heterochromatin-associated in Drosophila involved in heterochromatin maintenance and silencing (52). Further investigations will be necessary to precisely determine the nature of the role played by ssDNA binding at the yeast mating-type loci and telomeres. 


\section{ACKNOWLEDGMENT}

We thank Dr. Lustig for providing the pJC52 plasmid and Dr. G. Hager and S. John for critical reading of the manuscript.

\section{REFERENCES}

1. Rine, J., and Herskowitz, I. (1987) Four genes responsible for a position effect on expression from HML and HMR in Saccharomyces cerevisiae. Genetics 116, 9-22.

2. Loo, S., and Rine, J. (1994) Silencers and domains of generalized repression. Science 264, 1768-1771.

3. Hecht, A., Laroche, T., Strahl-Bolsinger, S., Gasser, S. M., and Grunstein, M. (1995) Histone H3 and H4 N-termini interact with SIR3 and SIR4 proteins: a molecular model for the formation of heterochromatin in yeast. Cell 80, 583-592.

4. Hecht, A., Strahl-Bolsinger, S., and Grunstein, M. (1996) Spreading of transcriptional repressor SIR3 from telomeric heterochromatin. Nature 383, 92-96.

5. Moazed, D., Kistler, A., Axelrod, A., Rine, J., and Johnson, A. D. (1997) Silent information regulator protein complexes in Saccharomyces cerevisiae: a SIR2/SIR4 complex and evidence for a regulatory domain in SIR4 that inhibits its interaction with SIR3. Proc. Natl. Acad. Sci. U.S.A. 94, 2186-2191.

6. Moretti, P., and Shore, D. (2001) Multiple interactions in Sir protein recruitment by Rap1p at silencers and telomeres in yeast. Mol. Cell. Biol. 21, 8082-8094.

7. Georgel, P. T., Palacios DeBeer, M., Pietz, G., Fox, C. A., and Hansen, J. C. (2001) Sir3-dependent assembly of supramolecular chromatin structures in vitro. Proc. Natl. Acad. Sci. U.S.A. 98, 8584-8589.

8. Luger, K., Mader, A. W., Richmond, R. K., Sargent, D. F., and Richmond, T. J. (1997) Crystal structure of the nuclesome core particle at the $2.8 \AA$ resolution. Nature 389, 251-260.

9. McBryant, S. J., Krause, C., Woodcock, C. L., and Hansen, J. C. (2008) The silent information regulator 3 protein, SIR3p, binds to chromatin fibers and assembles a hypercondensed chromatin architecture in the presence of salt. Mol. Cell. Biol. 28, 3563-3572.

10. Liaw, H., and Lustig, A. J. (2006) Sir3 C-terminal domain involvement in the initiation and spreading of heterochromatin. Mol. Cell. Biol. 26, 7616-7631.

11. Georgel, P. T., Tsukiyama, T., and Wu, C. (1997) Role of histone tails in nucleosome remodeling by Drosophila NURF. EMBO J. $16,4717-4726$.

12. Nikitina, T., Ghosh, R. P., Horowitz-Scherer, R. A., Hansen, J. C., Grigoryev, S. A., and Woodcock, C. L. (2007) MeCP2-chromatin interactions include the formation of chromatosome-like structures and are altered in mutations causing Rett syndrome. J. Biol. Chem. 282, 28237-28245.

13. Bell, S. P., Mitchell, J., Leber, J., Kobayashi, R., and Stillman, B. (1995) The multidomain structure of Orc1p reveals similarity to regulators of DNA replication and transcriptional silencing. Cell $83,563-568$.

14. Mumberg, D., Muller, R., and Funk, M. (1995) Yeast vectors for the controlled expression of heterologous proteins in different genetic backgrounds. Gene 156, 119-122.

15. Georgel, P., Demeler, B., Terpening, C., Paule, M. R., and van Holde, K. E. (1993) Binding of the RNA polymerase I transcription complex to its promoter can modify positioning of downstream nucleosomes assembled in vitro. J. Biol. Chem. 268, 1947-1954.

16. Hansen, J. C., Ausio, J., Stanik, V. H., and van Holde, K. E. (1989) Homogeneous reconstituted oligonucleosomes, evidence for saltdependent folding in the absence of histone H1. Biochemistry 28, 9129-9136.

17. Fletcher, T. M., and Hansen, J. C. (1995) Core histone tail domains mediate oligonucleosome folding and nucleosomal DNA organization through distinct molecular mechanisms. J. Biol. Chem. 270, 25359-25362.

18. Hansen, J. C., and Lohr, D. (1993) Assembly and structural properties of subsaturated chromatin arrays. J. Biol. Chem. 268, $5840-5848$.

19. Fletcher, T. M., Serwer, P., and Hansen, J. C. (1994) Quantitative analysis of macromolecular conformational changes using agarose gel electrophoresis: application to chromatin folding. Biochemistry 33, 10859-10863.
20. Becker, P. B., and Wu, C. (1992) Cell-free system for assembly of transcriptionally repressed chromatin from Drosophila embryos. Mol. Cell. Biol. 12, 2241-2249.

21. Dong, F., Hansen, J. C., and van Holde, K. E. (1990) DNA and protein determinants of nucleosome positioning on sea urchin $5 \mathrm{~S}$ rDNA gene sequences in vitro. Proc. Natl. Acad. Sci. U.S.A. 87, 5724-5728.

22. Georgel, P. T., and Robert, C. H. (2002) Differential core histone binding behavior: RNA polymerase I promoter region vs $5 \mathrm{~S}$ rDNA positioning DNA sequences. Cell Biochem. Biophvs. 37, $1-13$.

23. Panyutin, I. G., and Hsieh, P. (1993) Formation of a single base mismatch impedes spontaneous DNA branch migration. J. Mol. Biol. 230, 413-424.

24. Wyman, J., and Gill, S. J. (1990) Binding and Linkage, University Science Books, Hill Valley, CA.

25. Robert, C. H., Gill, S. J., and Wyman, J. (1988) Quantitative analysis of linkage in macromolecules when one ligand is present in limited total quantity. Biochemistry 27, 6829-6835.

26. Teif, V. B. (2007) General transfer matrix formalism to calculate DNA-protein-drug binding in gene regulation: application to OR operator of phage lambda. Nucleic Acids Res. 35, e80.

27. Shore, D., and Nasmyth, K. (1987) Purification and cloning of a DNA binding protein from yeast that binds to both silencer and activator elements. Cell 51, 721-732.

28. Buchman, A. R., Lue, N. F., and Kornberg, R. D. (1988) Connections between transcriptional activators, silencers, and telomeres as revealed by functional analysis of a yeast DNAbinding protein. Mol. Cell. Biol. 8, 5086-5099.

29. Johnson, L. M., Kayne, P. S., Kahn, E. S., and Grunstein, M. (1990) Genetic evidence for an interaction between SIR3 and histone H4 in the repression of the silent mating loci in Saccharomyces cerevisiae. Proc. Natl. Acad. Sci. U.S.A. 87, 6286-6290.

30. McBryant, S. J., Krause, C., and Hansen, J. C. (2006) Domain organization and quaternary structure of the Saccharomyces cerevisiae silent information regulator 3 protein, Sir 3 p. Biochemistry 45, 15941-15948.

31. Trifonov, E. N. (1991) DNA in profile. Trends Biochem. Sci. 16, 467-470.

32. Lilley, D. M. (2000) Structures of helical junctions in nucleic acids. O. Rev. Biophvs. 33, 109-159.

33. Declais, A. C., Fogg, J. M., Freeman, A. D., Coste, F., Hadden, J M., Phillips, S. E., and Liley, D M. (2003) The complex between a four-way DNA junction and T7 endoclease I. EMBO J. 22, 1398-1409.

34. Tanny, J. C., Dowd, G. J., Huang, J., Hilz, H., and Moazed, D. (1999) An enzymatic activity in the yeast Sir2 protein that is essential for gene silencing. Cell 99, 735-745.

35. Kristjuhan, A., Wittschieben, B. O., Walker, J., Roberts, D., Cairns, B. R., and Svejstrup, J. Q. (2003) Spreading of Sir3 protein in cells with severe histone $\mathrm{H} 3$ hypoacetylation. Proc. Natl. Acad. Sci. U.S.A. 100, 7551-7556.

36. Hoppe, G. J., Tanny, J. C., Rudner, A. D., Gerber, S. A., Danaie, S., Gygi, S. P., and Moazed, D. (2002) Steps in assembly of silent chromatin in yeast: Sir3-indelendent binding of Sir2/Sir4 complex to silencers and role for Sir2-dependent deacetylation. Mol. Cell. Biol. 22, 4167-4180.

37. Renauld, H., Aparicio, O. M., Zierath, P. D., Billington, B. L., Chhablani, S. K., and Gottschling, D. E. (1993) Silent domains are assembled continuously from the telomere and are defined by promoter distance and strength, and by SIR3 dosage. Genes Dev . 7, 1133-1145.

38. Strahl-Bolsinger, S., Hecht, A., Luo, K., and Grunstein, M. (1997) SIR2 and SIR4 interactions differ in core and extended telomeric heterochromatin in yeast. Genes Dev. 11, 83-93.

39. Pryciak, P. M., and Varmus, H. E. (1992) Nucleosomes, DNAbinding proteins, and DNA sequence modulate retroviral integration target site selection. Cell 69, 769-780.

40. Muthurajan, U. M., Park, Y. J., Edayathumangalam, R. S., Suto, R. K., Chakravarthy, S., Dyer, P. N., and Luger, K. (2003) Structure and dynamics of nucleosomal DNA. Biopolvmers 68, 547-556.

41. Grigoryev, S. A., and Woodcock, C. L. (1998) Chromatin structure in granulocytes. A link between tight compaction and accumulation of heterochromatin-associated protein (MENT). J. Biol. Chem. 273, 3082-3089.

42. Thomas, J. O., Rees, C., and Finch, J. T. (1992) Cooperative binding of the globular domains of histones $\mathrm{H} 1$ and $\mathrm{H} 5$ to DNA. Nucleic Acids Res. 20, 187-194.

43. Verschure, P. J., van der Kraan, I., de Leeuw, W., van der Vlag, J., Carpenter, A. E., Belmont, A. S., and van Driel, R. (2005) In vivo HP1 
targeting causes large-scale chromatin condensation and enhanced histone lysine methylation. Mol. Cell. Biol. 25, 4552-4564.

44. Hediger, F., and Gasser, S. M. (2006) Heterochromatin protein 1, don't judge the book by its cover. Curr. Opin. Dev. 16, 143-150.

45. Grigoryev, S. A. (2001) Higher-order folding of heterochromatin: protein bridges span the nucleoosme arrays. Biochem. Cell. Biol. 79, 227-241.

46. Dourns, B. D., Alexander, M. K., Smith, A. M., and Zakian, V. A. (1998) Sir proteins, Rif proteins, and Cdc13p bind Saccharomyces telomeres in vivo. Mol. Cell. Biol. 18, 5600-5608.

47. Virta-Pearlman, V., Morris, D. K., and Lundblad, V. (1996) Est1 has the properties of a single-stranded telomere end-binding protein. Genes Dev. 10, 3094-3104.

48. Lin, J. J., and Zakian, V. A. (1994) Isolation and characterization of two Saccharomyces cerevisiae genes that encode proteins that bind to (TG1-3)n single strand telomeric DNA in vitro. Nucleic Acids Res. 22, 4906-4913.
49. Konkel, L. M., Enomoto, S., Chamberlain, E. M., McCune-Zierath, P., Iyadurai, S. J., and Berman, J. (1995) A class of single-stranded telomeric DNA-binding proteins required for Rap1p localization in yeast nuclei. Proc. Natl. Acad. Sci. U.S.A. 92, 5558-5562.

50. Kyrion, G., Baokye, K. A., and Lustig, A. J. (1992) C-terminal truncation of RAP1 results in the deregulation of telomere size, stability, and function in Saccharomyces cerevisiae. Mol. Cell. Biol. 12, 5159-5173.

51. de Bruin, D., Kantrow, S. M., Liberatore, R. A., and Zakian, V. A. (2000) Telomere folding is required for the stable maintenance of telomere position effect in yeast. Mol. Cell. Biol. 20, 7991-8000.

52. Huertas, D., Cortés, A., Casanova, J., and Azorín, F. (2004) Drosophila DDP1, a multi-KH-domain protein, contributes to centromeric silencing and chromosome segregation. Curr. Biol. 14, $1611-1620$

BI801705G 